\title{
miRNA in a multiomic context for diagnosis, treatment monitoring and personalized management of metastatic breast cancer
}

\author{
Pavol Zubor*,‡,1,2, Peter Kubatka ${ }^{\ddagger 2,3}$, Zuzana Dankova ${ }^{\ddagger 2}$, Alexandra Gondova1, Karol \\ Kajo $^{4,5}$, Jozef Hatok ${ }^{6}$, Marek Samec ${ }^{1,2}$, Marianna Jagelkova ${ }^{1,2}$, Stefan Krivus ${ }^{1}$, Veronika \\ Holubekova ${ }^{2}$, Jan Bujnak ${ }^{7,8}$, Zuzana Laucekova1, Katarina Zelinova ${ }^{1,2}$, Igor Stastny ${ }^{1,2}$, \\ Marcela Nachajova1, Jan Danko ${ }^{1}$ \& Olga Golubnitschaja9, 10,11 \\ ${ }^{1}$ Department of Obstetrics \& Gynecology, Jessenius Faculty of Medicine, Comenius University in Bratislava, Martin University \\ Hospital, Martin, Slovak Republic \\ ${ }^{2}$ Biomedical Center Martin, Division of Oncology, Jessenius Faculty of Medicine, Comenius University in Bratislava, Martin, Slovak \\ Republic \\ ${ }^{3}$ Department of Medical Biology, Jessenius Faculty of Medicine, Comenius University in Bratislava, Martin, Slovak Republic \\ ${ }^{4}$ Department of Pathology, St Elizabeth Cancer Institute Hospital, Bratislava, Slovak Republic \\ ${ }^{5}$ Biomedical Research Center, Slovak Academy of Sciences, Bratislava, Slovak Republic \\ ${ }^{6}$ Department of Medical Biochemistry, Jessenius Faculty of Medicine, Comenius University in Bratislava, Martin, Slovak Republic \\ ${ }^{7}$ Department of Obstetrics \& Gynecology, Kukuras Michalovce Hospital, Michalovce, Slovak Republic \\ ${ }^{8}$ Oncogynecology Unit, Penta Hospitals International, Svet Zdravia, Michalovce, Slovak Republic \\ ${ }^{9}$ Radiological Clinic, Rheinische Friedrich-Wilhelms-University of Bonn, Bonn, Germany \\ ${ }^{10}$ Breast Cancer Research Center, Rheinische Friedrich-Wilhelms-University of Bonn, Bonn, Germany \\ ${ }^{11}$ Center for Integrated Oncology, Cologne-Bonn, Rheinische Friedrich-Wilhelms-University of Bonn, Bonn, Germany \\ *Author for correspondence: Tel.: +421 434203 242; Fax: +421 434134 185; pavol.zubor@jfmed.uniba.sk \\ ${ }^{\ddagger}$ Authors contributed equally
}

Metastatic breast cancer is characterized by aggressive spreading to distant organs. Despite huge multilevel research, there are still several important challenges that have to be clarified in the management of this disease. Therefore, recent investigations have implemented a modern, multiomic approach with the aim of identifying specific biomarkers for not only early detection but also to predict treatment responses and metastatic spread. Specific attention is paid to short miRNAs, which regulate gene expression at the post-transcriptional level. Aberrant miRNA expression could initiate cancer development, cell proliferation, invasion, migration, metastatic spread or drug resistance. An miRNA signature is, therefore, believed to be a promising biomarker and prediction tool that could be utilized in all phases of carcinogenesis. This article offers comprehensive information about miRNA profiles useful for diagnostic and treatment purposes that may sufficiently advance breast cancer management and improve individual outcomes in the near future.

First draft submitted: 21 January 2018; Accepted for publication: 9 May 2018; Published online: 18 July 2018

Keywords: breast cancer $\bullet$ individual outcome $\bullet$ metastasis $\bullet$ miRNA $\bullet$ personalized medicine $\bullet$ prediction $\bullet$ prevention

\section{Breast cancer}

\section{Statistics}

Breast cancer (BC) has been the most common cancer (25.2\%) and the leading cause of cancer-related death $(14.7 \%)$ in female populations worldwide for several years [1]. Despite the huge screening programs applied for early diagnosis and significant improvements in treatment algorithms, there are still about 1.67 million new cases with over a half of million disease-related deaths registered annually worldwide. These alarming data led the scientific community to recognize $\mathrm{BC}$ as a modern epidemic in the early 21 st century [1-3]. Certainly, currently applied screening programs have contributed to more diagnoses of $\mathrm{BC}$, which increase the overall prevalence recorded for the disease. However, permanently increasing $\mathrm{BC}$ incidence is a great worry to researchers, care givers 
and society at large. Noteworthy, BC is frequently linked to lifestyle-related risk factors that are modifiable, which opens a great deal of room for strongly under-represented targeted preventive measures in currently applied BC management [3]. On an optimistic note, advances in early cancer detection and modern adjuvant treatment have led to decreased disease-related mortality rates $[4,5]$.

Furthermore, several epidemiological studies confirmed an increasing incidence of metastatic BC (MBC) in young women, which is a very new phenomenon that needs, multiprofessional expertise, multicenter studies and innovative screening programs as clearly demonstrated by recently performed pilot projects [6-8]. Expressed in figures, for example, in the USA the increase of BC incidence in 25- to 39-year old women was from 1.53/100,000 in 1976 up to 2.90/100,000 in 2009 [6]. Data from Europe also show an increase in the number of new malignant $\mathrm{BC}$ cases in women under 45 years of age from 16.6 to $37.7 \%$ between the years 2002 and 2011 [9].

\section{$\mathrm{BC}$ characteristics}

$\mathrm{BC}$ is a heterogeneous group of neoplastic disorders with various morphologic signs and, therefore, has different clinical behaviors and outcomes [10]. Breast carcinomas can be classified according to the WHO's recommendations using histologic patterns as: invasive ductal carcinoma (80\%), followed by lobular carcinomas (10-15\%), whereas some of the others are rare [11]. The classification of these rare breast carcinomas is based on the dominating growth pattern and could be mucinous, papillary, medullary or cribriform [12]. The second classical morphologic prognostic factor is histologic grading, which is more important than the morphologic type for clinical management of patients with $\mathrm{BC}[13]$. The most widely used system is Bloom and Richardson's histologic grade, modified by Elston and Ellis in 1991 [14].

It is known that histopathological appearance alone does not reliably predict clinical behavior of the disease in individual patients [15]. Other pathologic features of BC provide additional insights into probable clinical behavior, including hormone receptors status, tumor size, nodal status and invasion of the lymphatics or blood vessels.

Very important factors included in therapeutic prediction are hormone receptors (estrogen receptor [ER] and progesterone receptor [PR]) and HER2, which must be measured on all newly diagnosed primary invasive BCs [16]. The majority of BCs are ER and/or PR (75\%) positive [16-18] and about 10-15\% of BCs also express the receptor protein HER2. It is a tyrosine kinase receptor involved in regulation of cellular growth and, therefore, HER2 is regarded as a prognostic and predictive factor in the context of anti-HER2-targeted therapy [19]. The extent of heterogeneity of $\mathrm{BCs}$ was enlarged by microarray techniques that interrogate concurrent expression patterns across a large number of transcripts and characterized the molecular signature of BC subtypes [20-23]. Nowadays, individual molecular BC subtypes are characterized as luminal A (50-60\% of BCs), luminal B (10-20\%), HER2 enriched (15-20\%), triple-negative BC (TNBC; basal-like; 10-20\%), claudin-low and a normal breast-like type [21,24-26]. All the entities have shown significant differences in terms of their incidence, risk factors, patient stratification, prediction, prognosis and treatment selection, and sensitivity to hormonal, chemotherapeutic and HER2-targeting therapy [15,27-30]. These intrinsic subtypes are identified using a combination of specific immunohistochemical analyses of hormone receptors, HER2 expression status and Ki-67 proliferative index as: luminal A-like type (ER-positive and/or PR-positive, HER2-negative, low proliferation), luminal B-like type (ER-positive and/or PR-positive, HER2-negative, high proliferation; or hormone receptor [HR]-positive and HER2-positive), HER2positive type (HR-negative and HER2-positive) and TNBC type (HR-negative and HER2-negative) [31].

Luminal subtypes tend to have slower metastatic spread, lower recurrence rates and better outcomes than HER2positive or basal subtypes [32-37]. The comparison of median survival (from time of first distal metastasis) showed that luminal types display longer overall survival (2.2 for luminal A and 1.6 years for luminal B) compared with HER2-positive subtype (1.3 years). The worst overall survival rate (0.7 years) was detected in the basal subtype [38]. The relapse rates also vary considerably between subtypes, with the highest rate for HER2-positive (51.4\%), followed by luminal B (42.9\%), basal (35.1\%) and luminal A (27.8\%) [32]. Despite advances in treatment, up to $30 \%$ of patients with early BC experience distant disease relapse [39].

\section{Metastatic breast cancer}

$\mathrm{BC}$ metastasis accounts for the majority of deaths from $\mathrm{BC}$ as $\mathrm{MBC}$ is often incurable and about $5 \%$ of patients already have distal metastases (M1) at the time of diagnosis [40,41]. Moreover, distal metastases occur in 10$15 \%$ of patients within the first 3 years. Distal metastases also developed in $33 \%$ of BC with no lymph node involvement at the time of diagnosis. However, the metastasis has a complex flow starting with local invasion of 
the surrounding tissue, followed by spreading into the blood or lymphatic vessels and ending with dissemination in distal organs $[38,40,42]$.

$\mathrm{MBC}$ is characterized by aggressive spread of metastases to distant organs, namely the liver, lung, brain and bones $[32,43,44]$. Bone metastases remain the most common metastatic site in luminal A and B BCs compared with other subtypes. Luminal subtypes of BC tend to also have an increased risk of lung and distant nodal recurrence and a lower rate of CNS metastases. HER2-positive tumors show a significantly higher risk for distant relapse compared with HER2-negative tumors and have higher metastatic potential in the CNS, despite the implementation of trastuzumab-based treatments for HER2-positive breast and lung cancers in the late 1990s [32,43]. On the other hand, it has low risk of bone metastasis [39]. Basal cancers were found to primarily metastasize to the lungs [39]. Although in BC-free populations primary brain tumors is a rare disorder, brain metastases are reported for more than $20 \%$ of patients affected by some specific BC subtypes [45,46], such as the TNBC with more than $50 \%$ of patients who die within the first 6 months of MBC diagnosis [47]. Early detection of BC metastasis is extremely important for treatment management and prediction of BC progression [40].

Noteworthy, the younger the age of the $\mathrm{BC}$ patients, the more aggressive metastatic disease can be expected with correspondingly poor outcomes [45] that strongly motivates, on one hand, identification of the targeted phenotype of the patients predisposed to $\mathrm{MBC}$ and, on the other hand, for the detection of a molecular signature specific for aggressive $\mathrm{BC}$ and metastatic disease. Modern analyses of circulating tumor cells show promising results in predicting and identifying the early stages of $\mathrm{BC}$ metastasis [40].

Investigations dedicated to the specific molecular signature of $\mathrm{MBC}$ still demonstrate moderate progress, though they have been carried over several decades prevalently utilizing a genomic approach. In PubMed, we found 2916 items dedicated to 'metastatic breast cancer Genomic' appearing first in the 1980s and currently demonstrating about 250 articles per year. The history of the application of proteomic technologies in the area is much younger: altogether 282 items were found in PubMed regarding 'metastatic breast cancer Proteomic' appearing for the very first time at the beginning of the millennium, which indicate the field is still in its infancy. Nevertheless, the early achievements are very promising. The proteomic approach seems to be capable to detect protein patterns characteristic for $\mathrm{MBC}$ versus non-MBC cell lines [48], metastatic lymph node tissues [49], differentiation between $\mathrm{MBC}$ and non-MBC forms in situ, and even to suggest protein targets for diagnostic and treatment purposes $[50,51]$.

\section{miRNAs in cancer}

\section{Biogenesis \& role of miRNAs}

miRNAs are short, noncoding RNAs of typically 22 nucleotides in length, which regulate gene expression at the post-transcriptional level and, thus, are responsible for proteome shaping [50,52] by binding to the $3^{\prime}$-untranslated regions ( $3^{\prime}$-UTR) of mRNA [53,54]. miRNAs are encoded by genomic DNA and are located mostly in intergenic regions (about 52\%), intronic regions of genes (40\%) and within exons (8\%) [55,56]. They represent the human genome information previously considered junk DNA, nowadays believed to be the hidden treasure regarding their potential relevance in diagnosis, prognosis, treatment and follow-up of cancer [57].

The biogenesis of miRNA is localized to the nucleus and cytoplasm and consists of several steps. In the nucleus, miRNA genes are transcribed mainly by RNA polymerase II and form primary transcripts with a hairpin structure (pri-miRNA). These pri-miRNAs are processed by the RNase III enzyme Drosha and its cofactor DGCR8 into a 70-100 nucleotide precursor pre-miRNA. Some pre-miRNAs are produced, alternatively, by the mirtron splicing pathway [50,58]. The pre-miRNAs are further exported to the cytoplasm by Exp5 and are processed by Dicer and RNase II enzyme that interacts with the $5^{\prime}$ - and $3^{\prime}$-end of pre-miRNA and form an about 22 nucleotide double-stranded mature miRNA. The functional strand of mature miRNA is incorporated into the RNA-induced silencing complex, which contains Ago protein and TNRC6 (GW182 protein), and is ready to bind its target mRNA (Figure 1A) [27,50,59]. Translation and maturation of miRNAs can be altered by several genetic and epigenetic mechanisms involved in any phase of the biogenesis (Figure 1B).

The sequence that is crucial for miRNA-mRNA binding is known as the 'seed sequence' and is mostly located at a position 2-8 base pairs from the $5^{\prime}$-end of the miRNA. It is an evolutionary conserved part that is complementary to the $3^{\prime}$-UTR of the target-matching mRNA (Figure 2) [54,60,61]. These bindings are able to suppress gene expression by targeting partially complementary regions of mRNAs and inhibiting protein translation. This binding has a crucial role in determining specific miRNA function, which is generally very variable. At the cellular level, miRNAs regulate various physiological and pathological processes such as differentiation, metabolism, proliferation and apoptosis and thus, their alteration can lead to malignant transformation by initiating rapid proliferation, cell 


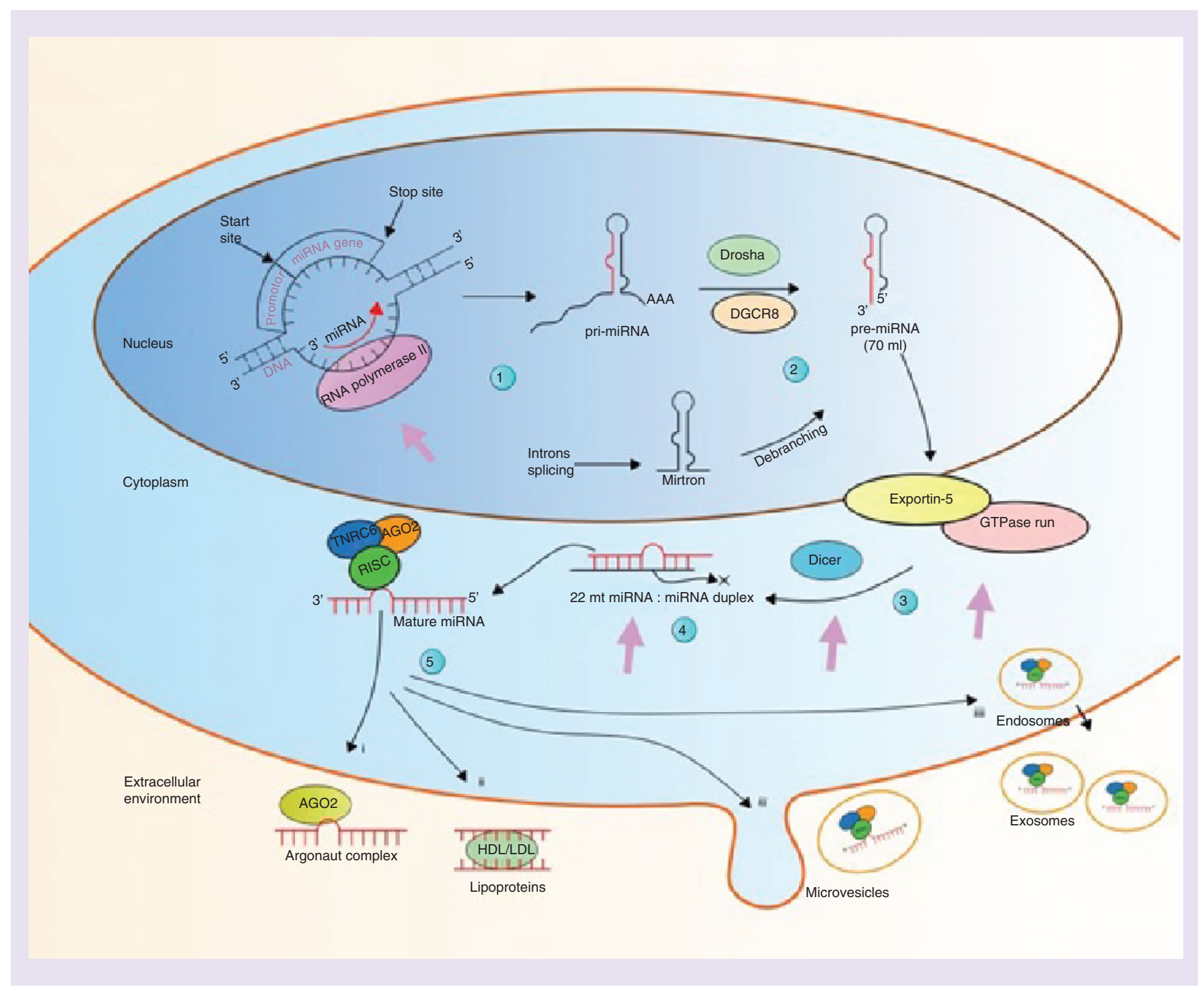

Figure 1. miRNA biogenesis, translational alterations and export. (A) Biogenesis: miRNAs are canonically transcribed from DNA in the nucleus by RNAse II, forming pri-miRNA with a length of about 70 nucleotides (1); processed by the RNA-binding protein DGCR8 and RNase III Drosha into pre-miRNAs with a truncated hairpin that bears a hairpin structure with a 2 nt overhang at the $3^{\prime}$-end (2); sequestered into the cytoplasm by Exp5 and Ran GTPase (3) and further cleaved by Dicer into 21-23 nucleotide duplexes (4) from which one strand of mature miRNA is formed. The mature strand can either bind to the target mRNA or be released to the extracellular environment (5). To exert its effect, miRNA requires RISCs and Ago proteins. An alternative miRNA biogenesis pathway from mirtrons substitutes Drosha cleavage with splicing. (B) Function: miRNA expression can be altered by several mechanisms (see violet arrows): chromosomal aberrations, genetic and epigenetic mechanisms, transcription factors that change the expression or the structure of the hairpin, mutations in EXPO5 leading to miRNA trapping in the nucleus, reduced Dicer expression and post-transcriptional editing (e.g., by ADARs). (C) Export: miRNAs can be transported to the extracellular environment either by being bound to RNA-binding proteins such as Ago2 (i), or by binding to lipoproteins (HDL or LDL) (ii), within microvesicles (iii) or loaded in exosomes that are released after endosomes, cytoplasmic membrane fusion (iv).

ADAR: Adenosine deaminases acting on RNA; HDL: High-density lipoprotein; LDL: Low-density lipoprotein; RISC: RNA-induced silencing complex.

migration and resistance to treatment [62]. The pivotal regulatory role of miRNAs in biological processes is well demonstrated in the literature [63,64]. To identify precise miRNA targets and to specify functional roles of miRNAs, several databases, algorithms and tools were developed: miRBase [65], miRWalk [66], mirDB [67], DIANA-TarBase [68], miRNA map [69], TargetScan [70], miRanda [71], PicTar [72] and others. 


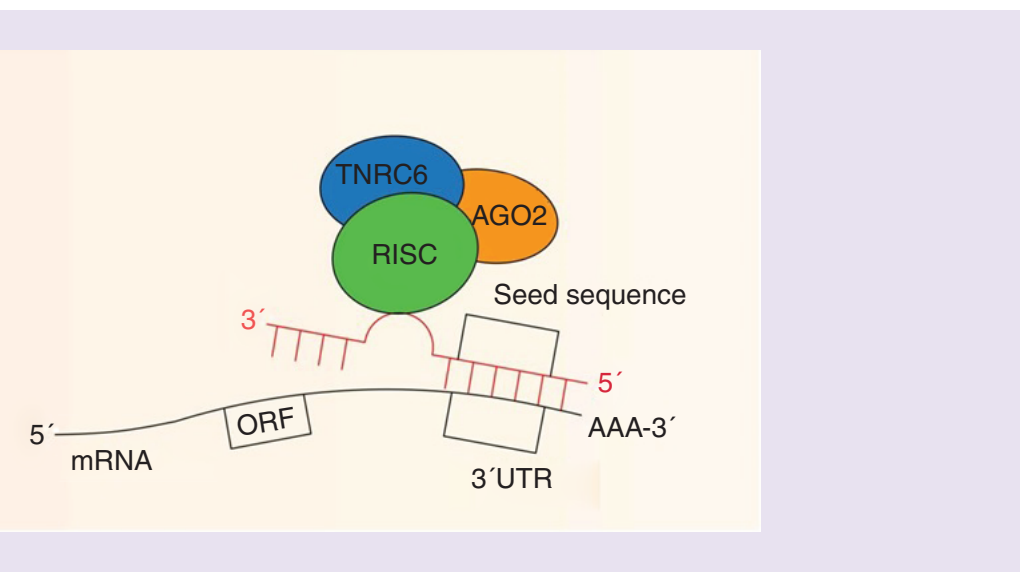

Figure 2. Binding of mature miRNA to the complementary $3^{\prime}$-UTR of targeted mRNA.

ORF: Open reading frame; RISC: RNA-induced silencing complex; UTR: Untranslated region.

\begin{tabular}{|c|c|c|}
\hline miRNA & Oncogenic miRNAs & Tumor-suppressor miRNAs \\
\hline Function & Promote tumorigenesis by inhibiting tumor-suppressor genes & Inhibition of oncogenes expression \\
\hline Types & $\begin{array}{l}\text { miR-10b [77] } \\
\text { miR-17-92 cluster [78] } \\
\text { miR-125b [79] } \\
\text { miR-18 [80] } \\
\text { miR-19a [81] } \\
\text { miR-20a [82] } \\
\text { miR-155 [83] } \\
\text { miR-569 [84] }\end{array}$ & $\begin{array}{l}\text { Let-7 family [81] } \\
\text { miR-145 [85] } \\
\text { miR-15a [86] } \\
\text { miR-16 [86] }\end{array}$ \\
\hline
\end{tabular}

A considerable amount of data confirmed the direct involvement of miRNA in the regulation of gene expression at the transcriptional level [73]. miRNAs may control both upregulation and downregulation of target gene transcription. Both these processes seem to be dependent on the presence of a DNA promoter region complementary to the seed sequence of a regulatory miRNA and on a noncoding transcript that overlaps the gene promoter itself [74]. The recognition between the complementary sequence on the noncoding RNA and miRNA arises through classic Watson and Crick base pairing. Currently, this mechanistic model is the most widely favored; however, more recent knowledge proposes that miRNA conducted recognition and interaction with promoter sequences may be accomplished via a direct interaction between RNA and single-stranded DNA complementary sequences. This alternative model of the role of miRNAs in regulation processes of gene expression points to direct and specific binding to DNA promoters, like transcription factors, and provide a platform for the localization of transcriptional regulators and chromatin modifying proteins at genomic loci [73,75].

\section{Regulatory role of miRNA in cancer biology}

miRNAs play a vital role in tumor initiation, progression, drug resistance and metastatic disease (Table 1) [7686]. Moreover, the tissue and cancer specificity of several miRNAs allows for detecting miRNA fingerprints for individual cancer subtypes $[54,87-89]$ that can be instrumental for screening programs, better patient stratification, therapy targeting and efficacy monitoring [50,54,90].

Dysregulation of expression of miRNAs causes altered functionality. As the predominant function of miRNA is, generally, to decrease target mRNA expression, upregulated miRNAs often act as oncogenes, oncomiRs (e.g., miR$10 b, m i R-21$ and $m i R-155)$, as they downregulate tumor-suppressor genes involved in cell differentiation. This leads to tumor formation, proliferation and invasion. On the other hand, tumor-suppressor miRNAs (e.g., miR-31, $m i R-125 b, m i R-200$ and $m i R-205)$ downregulate proteins with oncogenic activity and exhibit lower expression in cancer cells $[52,53]$. However, under certain cellular conditions, miRNA-mRNA binding could lead to increased expression [27,50]. Moreover, some miRNAs could act as an oncogene in one type of cells and as a suppressor in another as they are involved in various mechanisms and pathways [27,52,91,92]. Regarding cancer aggressiveness, 
several miRNAs also act as prometastatic factors, called metastamiRs (e.g., miR-10b, miR-21 and miR-373), or like metastasis suppressors (e.g., miR-31, miR-125b, miR-200 and miR-206) [53]. Here, the importance of miRNAs in cancer spread rises with the knowledge that not only oncogenic and tumor-suppressive transcription factors but also several epigenetic mechanisms like miRNA hypermethylation can modify miRNA profiles crucial for metastatic progression [52]. Consequently, individualized miRNA profiles are decisive for both tumor progression and suppression $[27,50]$.

\section{miRNAs in body fluids as promising biomarkers}

Apart from tumor microenvironment, miRNAs can be found and isolated from various body fluids including serum, plasma, saliva, urine, breast milk, seminal fluid, cerebrospinal fluids and others [93-95]. These miRNAs, called circulating miRNAs or extracellular miRNAs (ECmiRNAs), are remarkably stable and resistant to RNases, fluctuations in $\mathrm{pH}$, long storage periods and to multiple freeze/thaw cycles [93,96]. The stability is most probably caused by the transport mechanisms as miRNAs are conjugated in complexes, providing them with protection. ECmiRNAs can be released and transported: in membrane-derived vesicles, either in microparticles (microvesicles) or in smaller exosomes; in HDL or LDL lipoprotein complexes; in the Ago protein complex; or wrapped in large apoptotic bodies (Figure 1C) [97-99]. Exported ECmiRNAs can be taken up by a variety of recipients, even distant cells, where they can alter target gene expression. ECmiRNAs, thus, represent cell-cell communication that contributes in carcinogenesis to tumor progression, metastasis and therapy resistance [50,52,93,100-102]. Export of miRNAs most probably has a selective pattern and is not only passive. Cells secrete specific miRNAs due to cellular signals or environmental cues and load them into specific vesicles. Moreover, some miRNAs seem to be expressed only to be exported, as they were not detected in the parent cell, only in extracellular vesicles $[97,103]$.

Due to characteristics of the ECmiRNAs and noninvasive method of the acquisition mentioned in the 'miRNAs in cancer' section, miRNAs represent excellent detectable biomarkers and promising targets in cancer management $[100,104,105]$.

\section{Exploitation of miRNAs in BC prediction \& diagnostics}

Specific miRNA profiles are capable of differentiating between the individual breast tumor subtypes, namely luminal A, luminal B, basal-like, HER2-positive and normal breast-like [106-108], and possibly discriminate between HER2-positive and HER2-negative tumors [109]. Furthermore, miRNA profiles are differentially associated with lymph node metastasis, vascular invasion and/or higher proliferation index (members of let-7 family, miR-9-3 and miR-145), different tumor stage (miR-21 and miR-145) or metastatic spreading (miR-10b) [110-112]. To this end, plasma concentrations of miR-16, miR-107, miR-130a, miR-146a, miR-214 and miR-520 are associated with lymph node status, and miR-17, miR-21, miR-34a, miR-155, miR-210 and miR-1258 are linked to disease spread and metastases. The levels of miR-10b, miR-146a and miR-373 correlate with both features [113,114]. Noteworthy, miRNA profiles demonstrate some overlaps between Ki-67-positive/HER2-positive/ER-positive/PRpositive groups. Consequently, subtype-specific miRNA patterns should be analyzed for precise diagnosis rather than single miRNAs [115].

miRNA profiles characteristic for individual BC subtypes

Endocrine receptors positive $B C$ subtypes

Approximately $70 \%$ of breast malignancies are endocrine receptor (ER/PR) positive, controlling expression of downstream proteins and pathways $[27,116]$. In the invasive luminal subtypes, miRNA profiles include upregulation of miR-29c-5p. DCIS signature comprises 27 miRNAs in total including upregulated miR-21-5p and the miR-200 family and downregulated let-7 family members [117]. miRNA profiles in cancer tissue with ER-positive (miR-135b, miR-190, miR-217, miR-218, miR-299 and miR-342), PR-positive (miR-377, miR-520g, miR-520f-520c and miR-527-518a) and HER2 receptor status (miR-30e, miR-181c, miR-302c, miR-376b and miR-520d) have been identified. Thereby, miR-342 expression demonstrated the highest levels in ER-positive and HER2-positive luminal B tumors but the lowest ones in the triple-negative tumors; therefore, representing an attractive target for diagnostic, stratification and therapeutic purposes [118].

Furthermore, miRNA blood profiles seem to be dependent on the tumor's endocrine status, being differentially expressed (miR-155 and miR-182) in serum of women with hormone sensitive versus resistant BC and demonstrating lower levels for miR-155 but higher levels for miR-182 in PR-positive cases [119,120]. The molecular portrait of the luminal A-like BC subtype is further supported by the miR-29a, miR-181a and miR-652 signature [121]. 


\section{HER2-positive BC subtype}

HER2-positive BC is characterized by increased tumor aggressiveness and poor prognosis. miR-9, miR-125a, miR-125b, miR-200 and miR-3622b-5p are involved in regulating pathology relevant ERBB2 and ERBB3 and corresponding protein signaling pathways [122,123]. Thereby, upregulation of miR-210 is associated with trastuzumab resistance, being an important predictive biomarker for the therapeutic response [27,124]. Similarly, miR-9 has targeting potential to HER2 mRNA and increased responsiveness of BC to docetaxel and cyclophosphamide treatments [125]. Characteristics for the luminal tumor subtype plasma miR-130a, miR-146a and miR-373 are also differentially expressed in HER2-positive versus negative tumors [114,126]. To this end, miR-375 is the best representative reflecting better clinical outcomes under neoadjuvant chemotherapy with no relapse in HER2positive cancers. Increased levels of circulating miR-375 are also characteristic for ER/PR-negative status and inflammatory BC [127].

\section{TNBC \& miRNAs}

TNBC demonstrates highly heterogeneous profiles at clinical, pathophysiological and molecular biological levels, demonstrating negative hormone receptor status and highly aggressive tumors and early metastatic disease with poor prognosis. Currently, there are no specific diagnostic markers or effective therapeutic approaches elaborated that altogether result in lowering survival rates within the entire BC patient cohort. Subtype-specific miRNA profiles seem to be a powerful instrument to improve the overall situation in TNBC management, due to their ability to regulate pathways fundamental for its pathology, such as cellular growth, proliferation, cellular movement and migration, and extracellular matrix degradation [128-130].

It has been concretely shown that miR-9 and miR-155 are related to epithelial-mesenchymal transition in BC, which is more relevant for TNBC compared with other subtypes. However, their expression profiles inversely correlate with epithelial-mesenchymal transition phenotype; consequently, whereas high miR-9 expression is predictive of distant metastasis and poor disease-free survival, increased miR-155 indicates more positive outcomes [131]. Fingerprints of miR-16, miR-55, miR-125b, miR-374a, miR-374b, miR-421, miR-497 and miR-655 can be further predictive of distant metastasis-free survival in patients under 50 years of age, who are strongly affected by particularly poor outcomes of TNBC. Plasma-based screening may become possible utilizing miR-16, miR-21, miRNA-30a, miR-195-5p, miR-199a-5p and miR-495 profiles for early detection of TNBC [132,133]. Moreover, plasma miR-199a-5p expression levels significantly differ between pre- and postoperative stages, suggesting miR199a-5p to be highly specific for TNBC as a potential diagnostic marker and therapeutic target [134]. Table 2 summarizes miRNA profiles specific for individual BC subtypes [27,38,53,78,121,135-138].

\section{Primary tumor versus serum: miRNA profiles}

Although circulating miRNAs do not reflect the miRNA profiles within the tumor [139], it is a robust indicator for the tumor onset. miRNAs have been proven to be selectively secreted from malignant cells in the mammary gland, and expressed differently in the blood of healthy individuals and patients affected with BC [98]. Therefore, miRNAs hold promise as a future screening marker for $\mathrm{BC}$, because circulating miRNAs associated with neoplasia have the potential to detect cancer even in its earliest stages, and they can differentiate between various tumors, for example, in compliance with their histological features such as hormone receptors and the state of lymph nodes [140].

Only a few studies have evaluated and compared miRNA expressions between tumor tissue and serum. Chan et al. [141] aimed to compare miRNA profiles between tumor and serum samples in patients with BC. MiRNA profiles from paired $\mathrm{BC}$ tumors, normal tissue and serum samples taken from 32 patients were assessed. The authors found different expressions of the 20 most significant miRNAs in BC tumors including miR-10b, miR-21 and miR-145, which have been previously shown to be dysregulated in BC. Only seven miRNAs have been detected in increased levels in both tissues and serum, suggesting that miRNAs may be released into the serum selectively. Moreover, 16 of the 20 most significant miRNAs found differentially expressed in the serum were novel. In another clinical study, Zhu et al. [142] found that over 174 miRNAs were expressed differently between BC tumors and normal tissue, and only 109 miRNAs' expressions differed between serum from BC patients and healthy individuals. This comparison showed only ten common miRNAs. In addition, the study revealed that the changes in miRNA expressions between healthy and BC individuals were opposite in serum and tissue samples for 28 miRNAs. Due to inconsistencies in expression levels of miRNAs in different sample mediums, it seems that miRNA biomarkers (signatures) should be developed as tissue-specific. Recently, the article of Bahrami et al. [143] summarized preclinical and clinical investigations and described a list of several tissue-specific miRNAs: miR-7, miR-21, miR-145, miR- 


\begin{tabular}{|c|c|c|c|c|}
\hline \multirow[t]{2}{*}{ Molecular subtype of breast cancer } & \multicolumn{2}{|c|}{ Expression of nonmetastatic miRNAs } & \multicolumn{2}{|c|}{ Expression of metastatic miRNAs } \\
\hline & Upregulated & Downregulated & Upregulated & Downregulated \\
\hline \multirow[t]{10}{*}{ Luminal A } & miR-106a & $\operatorname{miR}-125 a-5 p$ & let-7a & miR-107 \\
\hline & miR-130a & $\operatorname{miR}-139-5 p$ & let-7b & miR-145a \\
\hline & miR-99b & miR-155 & let-7c & miR-148a \\
\hline & miR-182 & miR-195 & let-7f & \\
\hline & $\operatorname{miR}-30 a-3 p$ & $\operatorname{miR}-219-5 p$ & miR-155 & \\
\hline & $\operatorname{miR}-30 a-5 p$ & $\operatorname{miR}-24$ & miR-103a-3p & \\
\hline & miR-342-3p & miR-451 & miR-126 & \\
\hline & miR-425 & miR-99a & miR-16 & \\
\hline & miR-501-5p & & $\operatorname{miR}-17$ & \\
\hline & miR-92a & & miR-200c & \\
\hline \multirow[t]{3}{*}{ Luminal B } & miR-30a-3p & & miR-107 & \\
\hline & $\operatorname{miR}-30 a-5 p$ & & miR-26a & \\
\hline & $\operatorname{miR}-342-3 p$ & & & \\
\hline \multirow[t]{6}{*}{ TNBC } & miR-106a & $\operatorname{miR}-135 b$ & $\operatorname{miR}-17$ & \\
\hline & $\operatorname{miR}-150$ & $\operatorname{miR}-500 a-3 p$ & miR-200a & \\
\hline & miR-15a & & miR-200b & \\
\hline & miR-18a & & miR-20a & \\
\hline & miR-501-5p & & $\operatorname{miR}-519 a$ & \\
\hline & miR-92a & & & \\
\hline \multirow[t]{4}{*}{ HER2 positive } & miR-150 & $\operatorname{miR}-125 a-5 p$ & miR-155 & miR-148a \\
\hline & & miR-125a & $\operatorname{miR}-21$ & \\
\hline & & miR-125b & miR-19a & \\
\hline & & & miR-375 & \\
\hline \multirow[t]{5}{*}{ Normal-like } & miR-130a & miR-100-5p & miR-143 & miR-215 \\
\hline & & $\operatorname{miR}-139-5 p$ & miR-299-5p & \\
\hline & & miR-195 & miR-335 & \\
\hline & & $\operatorname{miR}-432-5 p$ & miR-411 & \\
\hline & & $\operatorname{miR}-497-5 p$ & miR-452 & \\
\hline $\begin{array}{l}\text { †Metastatic or nonmetastatic. } \\
\text { TNBC: Triple-negative breast cancer. } \\
\text { Data taken from }[27,38,53,78,121,135-138] .\end{array}$ & & & & \\
\hline
\end{tabular}

155/154, miR-182, miR-203 and miR-213, and abnormal activation in BC patients extending to the circulation: miR-16, miR-18a, miR-21, miR-145, let-151a and miR-155, suggesting their values as noninvasive markers and, in addition, as a potential approach to overcome chemoresistance.

Primary tumor versus distant metastases: miRNA profile

As was described earlier, intrinsic (molecular) BC subtypes show a site-specific pattern of metastases formation [144,145], which occur predominantly in the brain and bones. Probably due to the difficulty to obtain metastatic samples, up to now only a few studies compared miRNA expression profiling of either primary breast tumors and their distant metastases or circulating miRNA and metastases [146-148]. Generally, it seems that the miRNA expression pattern of primary and metastatic samples is similar, but with higher expression of metastamiRs [146]. Based on the results of Schrijver et al. [146], miR-106b-5p could be an independent predictor of lung and GI metastases, miR-7-5p of skin and miR-1273g-3p of ovarian metastases. As these data represent just the first studies and preliminary results, several aspects remain to be elucidated and methods validated.

\section{Methodological challenges of miRNA profiling}

The earlier-mentioned data point out the necessity for the development of standard protocols for blood specimen collection and processing, as well as disclosure of detailed clinical patient information in reports. Many of the 


\begin{tabular}{|c|c|c|c|c|c|}
\hline miRNA & Source & Drug & Expression & Effect & Ref. \\
\hline let-7 & Patient & Epirubicin, cyclophosphamide & Low & Not stated & [154] \\
\hline miR-10b & Patient & Epirubicin, cyclophosphamide & Low & Not stated & [154] \\
\hline $\operatorname{miR}-21$ & Patient & Epirubicin, cyclophosphamide & High & Not stated & [154] \\
\hline $\operatorname{miR}-34$ & Patient & Epirubicin, cyclophosphamide & Low & Not stated & [154] \\
\hline miR-34a & Patient & Anthracycline & High & Antitumor effect & [153] \\
\hline miR-122 & Patient & Anthracycline & High & Antitumor effect & [153] \\
\hline $\operatorname{miR}-125 b$ & Cell line & Letrozole, anastrozole, paclitaxel & High & Resistance & {$[79,156]$} \\
\hline miR-134 & $\begin{array}{l}\text { Cell line with artificially } \\
\text { enhanced miR-134 }\end{array}$ & Cisplatin & - & $\begin{array}{l}\text { Sensitivity to cisplatin-induced } \\
\text { apoptosis }\end{array}$ & [157] \\
\hline $\operatorname{miR}-155$ & Patient & Epirubicin, cyclophosphamide & Low & Not stated & [154] \\
\hline $\operatorname{miR}-181$ & Cell line & Doxorubicin & High & Chemoresistance, cancer cell survival & [158] \\
\hline miR-195 & Patient & Epirubicin, cyclophosphamide & High & Not stated & [154] \\
\hline $\operatorname{miR}-200 \mathrm{c}$ & Patient & Epirubicin, cyclophosphamide & Low & Not stated & [154] \\
\hline miR-205 & Patient & Epirubicin, cyclophosphamide & Low & Not stated & [154] \\
\hline miR-205 & Cell line & Letrozole, anastrozole & High & Resistance & [79] \\
\hline $\operatorname{miR}-221$ & Patient & Epirubicin, cyclophosphamide & High & Not stated & [154] \\
\hline $\operatorname{miR}-424$ & Cell line & Letrozole, anastrozole & Low & Resistance & [79] \\
\hline miR-451 & Patient & Doxorubicin/cyclophosphamide, taxane & Low & Resistance, worse survival & [155] \\
\hline miR-3200 & Patient & Taxane & Low & $\begin{array}{l}\text { Higher residual cancer burden and } \\
\text { relapse rates }\end{array}$ & [155] \\
\hline
\end{tabular}

discrepancies observed in results within clinical research can be attributed to this early step in the process [149]. Considerable effort has been made in the methodological progress of circulating miRNA detection profiling. Currently, several methodological approaches have emerged to evaluate circulating miRNA levels including quantitative real time PCR (qRT-PCR), microarrays and next-generation sequencing (NGS). Each method has its advantages and disadvantages regarding simplicity, quantification and validity. Concerning the significance of quality control in qRT-PCR analysis or in mRNA microarray, the quality and quantity of the circulating miRNA strongly affect the detection level of analysis. Several techniques, such as phenol-chloroform-based RNA extraction or extraction kits, are available; nonetheless, there is no gold standard for assessing circulating miRNA. Prospective studies are needed to find a consensus on this important issue [149].

The discussion about the advantages and disadvantages of qRT-PCR, microarray and NGS methods is necessary to consider the complexity, throughput, sensitivity/specificity, time factor, required RNA input and expected costs. qRT-PCR is the most useful for assessing several known specific miRNAs. It is easily and quickly performed; moreover, it is characterized by the highest sensitivity, specificity, accuracy and reproducibility compared with other methods. Microarray and NGS are used for high throughput or unknown targets; however, the accuracy, reproducibility and costs may be a problem. In contrast to qRT-PCR, microarrays cannot be used for absolute quantification of miRNA levels because of their lower sensitivity and specificity [150]. Similarly, validation of the NGS method is ongoing to determine its specificity and sensitivity in detecting circulating miRNA [151].

Despite recent reductions in the total costs for microarrays and NGS methods and their improved computational accuracy, qRT-PCR remains the most widely used method for validating the results from microarray and NGS, because it still shows the highest relative sensitivity and specificity. Further effort is required to establish standard protocols for blood specimen collection, processing and analysis of circulating miRNAs regarding BC patients.

\section{miRNAs in therapy}

miRNA profiles in response to chemotherapy: therapy prediction, monitoring \& prognosis miRNA profiles sufficiently vary under chemotherapy applied to BC patients, impacting survival rates and diseasefree survival [152]. Consequently, they affect the reaction toward treatment and therapy resistance [153,154]. Plasma miRNA profiles vary dynamically during neoadjuvant chemotherapy and antihormonal treatment, differentially correlating with the therapy prognosis in individual BC subtypes [79,155-158]. Table 3 summarizes preliminary data, which should be validated in multicentered, large-scale studies. 


\begin{tabular}{|c|c|c|c|c|}
\hline Breast cancer subtype & Number of cases & $\begin{array}{l}\text { Influenced parameter of the } \\
\text { treatment monitoring }\end{array}$ & miRNA signature & Ref. \\
\hline Early stage, ER+ & 23 & Disease recurrence & miR-377-5p, miR-633b, miR-548t and miR-3648 & [159] \\
\hline $\mathrm{ER}^{+}$ & $\begin{array}{l}\text { Meta-analysis of five } \\
\text { studies }\end{array}$ & Disease recurrence and survival & $\begin{array}{l}\downarrow \mathrm{miR} 29 \mathrm{c}, \text { miR30 family and let-7a, } \uparrow \mathrm{miR} 221 / 222, \\
\text { miR22 and miR224 }\end{array}$ & [160] \\
\hline HR + HER2- & 611 & Disease recurrence & $\begin{array}{l}\text { miR-21, miR-30c, miR-181a, miR-181c, miR-125b, } \\
\text { miR-7, miR-200a, miR-135b, miR-22 and miR-200c }\end{array}$ & [161] \\
\hline HER2+ & 110 & Disease-free survival & miR-4734 and miR-150-5p & [162] \\
\hline $\begin{array}{l}\text { HER2+, inflammatory breast } \\
\text { carcinoma }\end{array}$ & 113 & $\begin{array}{l}\uparrow \text { Progression-free and overall } \\
\text { survival time }\end{array}$ & $\uparrow \operatorname{miR}-19 a$ & [163] \\
\hline TNBC & 130 & $\begin{array}{l}\text { Disease recurrence and overall } \\
\text { survival }\end{array}$ & miR-18b, miR-103, miR-107 and miR-652 & [164] \\
\hline Both TNBC and HR+ & 90 & Disease recurrence & $\begin{array}{l}\uparrow m i R-21-5 p, \text { miR-375, miR-205-5p and miR-194-5p, } \\
\downarrow m i R-382-5 p, \text { miR-376c-3p and miR-411-5p }\end{array}$ & [165] \\
\hline TNBC - BRCA1 or sporadic & 50 & Overall survival & $\uparrow \mathrm{miR}-214$ & [166] \\
\hline $\begin{array}{l}\text { Metastatic CTC-positive or } \\
\text { negative }\end{array}$ & 269 & $\begin{array}{l}\text { The onset of metastasis up to } 2 \\
\text { years prior to clinical diagnosis, } \\
\text { overall survival }\end{array}$ & $\begin{array}{l}\text { miR-141, miR-144, miR-193b, miR-200a, miR-200b, } \\
\text { miR-200c, miR-203, miR-210, miR-215, miR-365, } \\
\text { miR-375, miR-429, miR-486-5p, miR-801, miR-1260 } \\
\text { and miR-1274a. Moreover, miR-200a, miR-200b, } \\
\text { miR-200c, miR-210, miR-215 and miR-486-5p }\end{array}$ & [167] \\
\hline
\end{tabular}

Thus, circulating miRNA profiles provide a very promising tool for the prediction of the most optimal therapeutic modalities and evaluation of therapeutical efficacy. Table 4 shows specific miRNA signatures for treatment monitoring, reflecting $\mathrm{BC}$ subtypes.

Beside the association analyses, several preclinical and clinical studies are focused on miRNA detection and aberrant expression patterns during BC treatment [168]. These studies analyze miRNA changes either generally in the context of sensitivity of BC patients to neoadjuvant and adjuvant chemotherapy [169], or are focused on the specific treatment, for example, with herceptin combined with other chemotherapy [170], anthracyclines [171], application of tamoxifen or antiaromatases [172].

Results of these studies together with pharmacological efforts and technological possibilities have great potential for clinical applications in the near future.

miRNA as targets \& tools in clinical therapy

Since miRNAs participate in cellular proliferation, differentiation, migration and apoptosis, dysregulation of miRNA expression is involved in tumorigenesis and metastatic activity, correlating with disease progression and recurrence [53,173-175]. Consequently, miRNAs can be used as novel targets in BC treatment [54,59] and several methods for that have been suggested (Figure 3). The first method for inhibiting miRNA in BC utilizes sponges, transcripts with antisense sequences of miRNA, which can bind endogenous miRNAs in cells and inhibit their function in cancer progression. Sponges can be delivered in vitro or in vivo. For in vitro delivery, they are transfected via plasmids or via viral particles [54,176]. Synthetic sponges for miR-183, miR-96 and miR-182 have been created using lentiviral vectors for delivery of cluster sponges and demonstrating a significantly decreased expression of the targeted miRNA cluster [177].

The second method is based on inhibition of miRNAs by delivery of antisense synthetic 17-22 nt oligonucleotides that are designed to bind endogenous mature miRNAs. These antisense synthetic 17-22 nt oligonucleotides are highly unstable due to degradation by nucleases. Therefore, short synthetic oligonucleotides were additionally modified, for example, by changing their phosphate-backbone chemistry to stabilize them in the cell. They are known as 'antagomiRs' and may be delivered in vivo, for example, using viral particles, a liposomal delivery system or nanoparticles-mediated delivery [54,174,178]. AntagomiRs very effectively inhibit tumor growth, migration and invasion [179-181].

The third method, called Inforna, is based on the repression of transcription or transcript processing of miRNAs acting as oncomiRs (oncogenic miRNAs) by binding of small lead molecules to the Dicer or Drosha processing part. Velagapudi et al. constructed small bioactive molecules and by their application inhibited the miRNA hairpin precursor of miR-98m, which resulted in downregulated expression of the oncomiR. This methodology is 
(A)

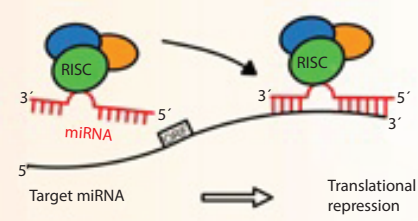

(B)

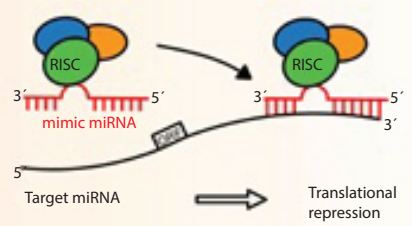

(c)

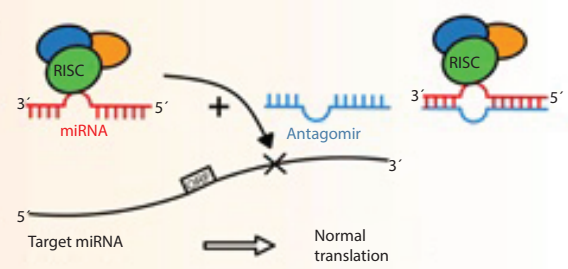

(D)

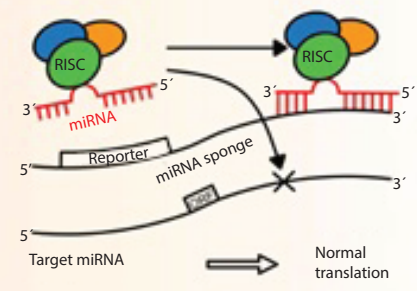

(E)

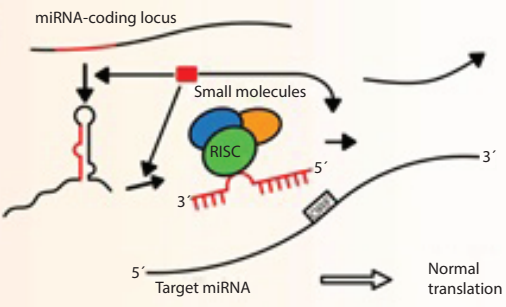

Figure 3. Methods applied to inhibit cancer progression by dysregulation of mRNA translation by miRNA. (A) Normal miRNA:mRNA binding resulting in translational repression, (B) miRNA mimics substitute downregulated miRNAs and bind to target mRNA, which results in translational repression, (C) antagomiRs bind to miRNA, thus inhibiting miRNA:mRNA binding leading to mRNA translation, (D) synthetic miRNA sponges scavenge complementary miRNA resulting in normal translation of targeted mRNA and $(E)$ inhibition of miRNA transcription and biogenesis by small molecules.

RISC: RNA-induced silencing complex. 
similarly sensitive to using antisense oligonucleotides but has no problems with delivery into cells or with immune responses [182].

The fourth technology applied in cases when miRNAs are downregulated is based on the supply of short nucleotide sequences similar to miRNA. As these synthetic RNA molecules mimic endogenous mature miRNA, they are called miRNAs 'mimics'. In the cancer tissue where the expression of tumor-suppressor miRNAs is low, these synthetic miRNAs can restore antitumor activity [27,54]. The first cancer-targeted miRNA drug is a liposome-based miR-34 mimic already entering Phase I clinical trial [54].

\section{Challenges of miRNA-based therapy delivery}

Delivery of miRNA into cancer cells is a challenging step in the overall approach of the targeted therapy [54,183]. The main problems to be resolved are: the poor penetration of miRNA into cancer tissues, degradation of antagomiRs and miRNA mimics without modification in tissues or plasma, miRNA-induced immune responses, neurodegeneration, neurotoxicity, low efficiency of gene silencing, and off-target effects of miRNAs in cancer cell (unmatching) [183,184]. Several technologies have been proposed (Figure 4) considering two main approaches for targeted delivery of miRNAs based on either viral or nonviral systems [185]. Although nonviral delivery systems are less effective, they are less immunogenic, highly biocompatible and unlimited in nucleic acid-loading capacity [186188]. One method of chemical nonviral delivery is based on synthetic polymers or dendrimers; another system utilizes lipoplex (liposome-based system) preventing degradation of miRNA inside the complex [186]. This system is characterized by low toxicity and has been demonstrated to be efficient in a mouse BC model [189] and MBC [190]. Inorganic carriers, such as carbon or gold nanoparticles, are utilized as an alternative nonviral delivery system, which have been demonstrated to be beneficial, nontoxic and nonimmunogenic [187], offering targeted inhibition of cancer progression [191].

Viral delivery systems utilize several types and subtypes of the viral vectors (retrovirus, adenovirus, adenoassociated virus and lentivirus) with high transfecting ability and expression levels targeting delivery of antagonist miRNA or miRNA mimics into cancer cells [180,192]. miRNA viral-based delivery systems are effective in inhibiting MBC but suffer from high immunogenicity and potential mutagenesis by viral particles $[183,185,193]$. The review by Abba et al. provides comprehensive information about the challenges of miRNA therapeutic techniques [54].

\section{What approach is currently applied?}

$\mathrm{BC}$ diagnostics are currently based on clinical and physical examinations, histopathology, imaging mammography and ultrasound MRI. Each method has several advantages and disadvantages. The noninvasive ultrasound is considered to be a safe tool, but it cannot be used to screen many of the cancers, mostly at ages above 40 years. Mammography screening is frequently not efficient enough for early tumor detection. Histopathological biopsy analysis is an invasive approach and needle biopsy extracts represent small amounts of the malignant tissue, which is not representative for the entire tumor heterogeneity, and the metastatic spread is not considered at all by this operation. Surgically resected primary tumor alone does not provide sufficient information about future disease development, seeding and specific biological characteristics of (potential) metastases, which are decisive for individual outcomes.

Therefore, there is an enormous effort to find noninvasive biomarkers that could be utilized not only in early diagnostics but could also specify tumor type, predict response to treatment and occurrence of metastases. Significant progress in understanding the cancer-related mechanisms has been achieved in epigenomics by the discovery of the central role of miRNAs in regulating protein expression. Currenlty, the miRNA signature is believed to be an important biomarker in each phase of carcinogenesis [194,195].

With the rapid development of NGS, massive multi-omics data for BC have been generated in the last years. The systematic integration of multi-omics data seems to be a very effective tool in the diagnosis of specific cancer subtypes and finding novel biomarkers [196]. In this regard, the Multi-Omics Breast Cancer Database (MOBCdb), a simple and easily accessible repository that includes genomic, transcriptomic, epigenomic, clinical and drug response data of different BC subtypes, was recently introduced. MOBCdb allows users to retrieve miRNA expression, but also simple nucleotide variation, gene expression, DNA methylation and specific drug response data by various search modes. The genome-wide browser of the MOBCdb offers an interface for visualizing multiomics data of multiple samples simultaneously. Moreover, the survival module shows survival analyses for all or some of the samples by using data of the three -omics [197]. MOBCdb is a useful tool for clinicians and scientists, which enables them to identify and translate potential novel biomarkers into predictive, preventive and personalized medicine. 
(A)

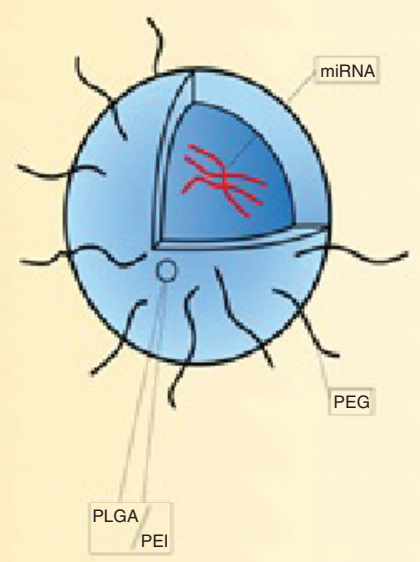

(B)

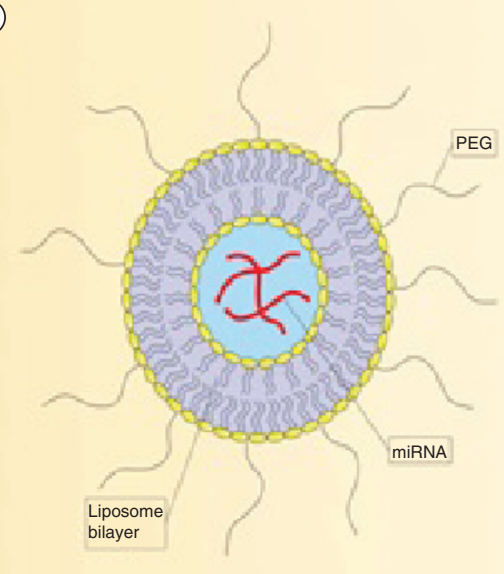

(C)

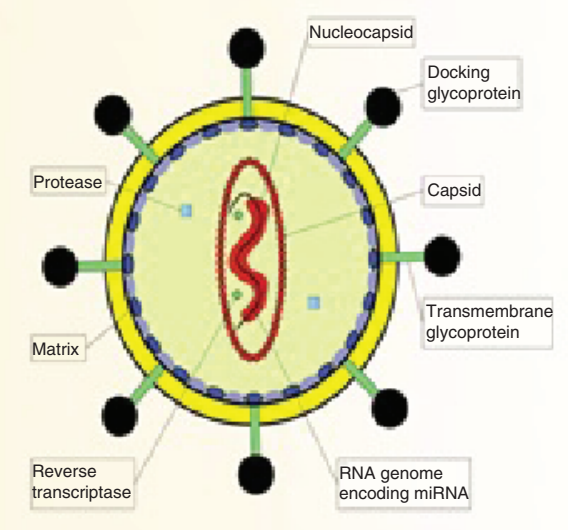

(D)

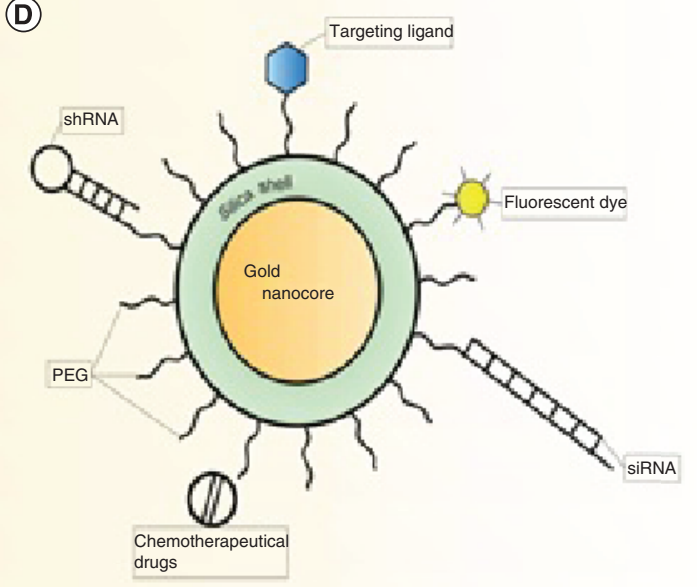

Figure 4. Delivery strategies for miRNAs in cancer treatment. (A) Polymer (PLGA or PEI)-based delivery system, (B) liposome-based delivery system, (C) viral vector and (D) gold nanoparticle.

PEI: Polyethylenimine; PLGA: poly(lactide-co-glycolide).

\section{Conclusion \& future perspective}

Individualized patient profiles are crucial for effective BC prediction, prevention and personalization of the services provided to improve $\mathrm{BC}$ management. Huge multiomic research, such as genomics, proteomics, metabolomics, epigenomics, including miRNAs, has been focused on complex understanding of biological functions and dynamics of specific diseases, including BC. Revealed results represent a very promising base for early and innovative screening programs, prediction of disease and its development, and specific characterization of individual BC subtypes that should assist in optimized individual-targeted therapy selection with minimal side effects and high efficiency. By early screening, precise diagnostics and individual follow-up, we should significantly decrease BC incidence, prolong life and, most importantly, improve quality of life and treatment outcomes for women. 


\section{Executive summary}

- Growing evidence demonstrates that the miRNA profiles play a central role in the regulation of the functional pathways, tumor biology and metastatic breast cancer (MBC).

- Aberrational miRNAs have the potential to induce cancer initiation, increase tumor cell proliferation, progression, invasion, migration, dissemination and metastatic spread or drug resistance.

- Individual miRNA profiles hold promise as a multifunctional biomarker for MBCs.

- miRNAs provide information for identifying and characterizing individual breast cancer (BC) subtypes, which is particularly important for accurate prediction of aggressively metastasizing subtypes such as triple-negative BC and inflammatory BC.

- The specific miRNA profiles have been linked to all stages along the metastatic cascade in BC.

- It has been shown that miRNAs may be instrumental for identifying a subtype-specific response to treatment and have the potential to predict the risk of recurrence.

- The plasma miRNA profiles could be used as a robust biomarker for screening, prognosis, treatment management, recurrence prediction and follow-up.

- The altered miRNA profiles reliably indicate the risk of BC clinical onset within 18 months of observation.

- It is suggested that specific miRNA profiles are an essential tool in individualized patient profiling for prediction, prevention and personalized treatment in overall BC management.

Financial \& competing interests disclosure

This work was supported by the following organizations: European Association for Predictive, Preventive and Personalised Medicine, EPMA, Brussels, Belgium; Slovak Research and Development Agency (under the contract no. APVV-16-0021), the Scientific Grant Agency, Ministry of Education, Science and Research, Slovak Republic and the VEGA Grant Agency (1/0124/17), Ministry of Education, Science and Research, Slovak Republic. The authors have no other relevant affiliations or financial involvement with any organization or entity with a financial interest in or financial conflict with the subject matter or materials discussed in the manuscript. This includes employment, consultancies, honoraria, stock ownership or options, expert testimony, grants or patents received or pending or royalties.

No writing assistance was utilized in the production of this manuscript.

Open access

This work is licensed under the Attribution-NonCommercial-NoDerivatives 4.0 Unported License. To view a copy of this license, visit http://creativecommons.org/licenses/by-nc-nd/4.0/

\section{References}

Papers of special note have been highlighted as: $\bullet$ of interest; $\bullet \bullet$ of considerable interest

1. Ferlay J, Soerjomataram I, Dikshit R. Cancer incidence and mortality worldwide: sources, methods and major patterns in GLOBOCAN 2012. Int. J. Cancer 136, 359-386 (2015).

2. Schneider PA, Zainer MCH, Kubat KCH et al. The breast cancer epidemic: 10 facts. Linacre Q 81, 244-277 (2014).

3. Simbrich A, Wellmann I, Heidrich J, Heidinger O, Hense HW. Trends in advanced breast cancer incidence rates after implementation of a mammography screening program in a German population. Cancer Epidemiol. 44, 44-51 (2016).

4. Siegel R, Ma J, Zou Z, Jemal A. Cancer statistics, 2014. CA Cancer J. Clin. 64, 9-29 (2014).

5. Narod SA, Iqbal J, Miller AB. Why have breast cancer mortality rates declined? J. Cancer Policy 5, 8-17 (2015).

6. Johnson RH, Chien FL, Blever A. Incidence of breast cancer with distant involvement among women in the United States, 1976 to 2009. JAMA 309, 800-805 (2013).

7. Zubor P, Gondova A, Polivka J Jr et al. Breast cancer and Flammer syndrome: any symptoms in common for prediction, prevention and personalised medical approach? EPMA J. 8, 129-140 (2017).

8. Bubnov R, Polivka J Jr, Zubor P, Koniczka K, Golubnitschaja O. "Pre-metastatic niches" in breast cancer: are they created by or prior to the tumour onset? "Flammer Syndrome" relevance to address the question. EPMA J. 8, 141-157 (2017).

9. Radziszewska UA, Borowska KB, Lampart GM et al. The incidence of breast cancer in population of young women from Podkarpackie province in 2002-2011. Contemp. Oncol. 20, 176-184 (2016).

10. Coleman WB, Anders CK. Discerning clinical responses in breast cancer based on molecular signatures. Am. J. Pathol. 187, 2199-2207 (2017). 
11. Lakhani SR, Ellis IO, Schnitt SJ, Tan PH, Van de Vijver MJ (Ed.). WHO Classification of Tumours of the Breast (Volume 4). IARC Press, Lyon, France, 143-147 (2012).

12. Russnes HG, Lingjærde OC, Børresen-Dale AL, Caldas C. Breast cancer molecular stratification: from intrinsic subtypes to integrative clusters. Am. J. Pathol. 187, 2152-2162 (2017).

13. Schwartz AM, Henson DE, Chen D, Rajamarthandan S. Histologic grade remains a prognostic factor for breast cancer regardless of the number of positive lymph nodes and tumor size: a study of 161-708 cases of breast cancer from the SEER Program. Arch. Pathol. Lab. Med. 138, 1048-1052 (2014).

14. Elston CW, Ellis IO. Pathological prognostic factors in breast cancer. I. The value of histological grade in breast cancer: experience from a large study with long-term follow-up. Histopathology 19, 403-410 (1991).

15. Goddard ET, Hill RC, Barrett A et al. Quantitative extracellular matrix proteomics to study mammary and liver tissue microenvironments. Int. J. Biochem. Cell. Biol. 81, 223-232 (2016).

16. Duffy MJ, Harbeck N, Nap M et al. Clinical use of biomarkers in breast cancer: updated guidelines from the European Group on Tumor Markers (EGTM). Eur. J. Cancer 75, 284-298 (2017).

17. Fisher B, Redmond CK, Fisher ER. Evolution of knowledge related to breast cancer heterogeneity: a 25-year retrospective. J. Clin. Oncol. 26, 2068-2071 (2008).

18. Early Breast Cancer Trialists' Collaborative Group (EBCTCG). Effects of chemotherapy and hormonal therapy for early breast cancer on recurrence and 15-year survival: an overview of the randomised trials. Lancet 365(9472), 1687-1717 (2005).

19. Loibl S, Gianni L. HER2-positive breast cancer. Lancet 389, 2415-2429 (2017).

20. Perou CM, Jeffrey SS, van de Rijn M et al. Distinctive gene expression patterns in human mammary epithelial cells and breast cancers. Proc. Natl Acad. Sci. USA 96, 9212-9217 (1999).

21. Perou CM, Sørlie T, Eisen MB et al. Molecular portraits of human breast tumours. Nature 406, 747-752 (2000).

22. Ross DT, Scherf U, Eisen MB et al. Systematic variation in gene expression patterns in human cancer cell lines. Nat. Genet. 24, 227-235 (2000).

23. Prat A, Pineda E, Adamo B et al. Clinical implications of the intrinsic molecular subtypes of breast cancer. Breast 24, 26-35 (2015).

24. Haakensen VD, Lingjaerde OC, Lüders $\mathrm{T}$ et al. Gene expression profiles of breast biopsies from healthy women identify a group with claudin-low features. BMC Med. Genomics 24, 77 (2011).

25. Prat A, Fan C, Fernández A et al. Response and survival of breast cancer intrinsic subtypes following multi-agent neoadjuvant chemotherapy. BMC Med. 13, 303 (2015).

26. Eroles P, Bosch A, Pérez-Fidalgo JA, Lluch A. Molecular biology in breast cancer: intrinsic subtypes and signaling pathways. Cancer Treat. Rev. 38, 698-707 (2012).

27. Kurozumi S, Yamaguchi Y, Kurosumi M, Ohira M, Matsumoto H, Horiguchi J. Recent trends in microRNA research into breast cancer with particular focus on the associations between microRNAs and intrinsic subtypes. J. Hum. Genet. 62, 15-24 (2017).

28. Chung CH, Bernard PS, Perou CM. Molecular portraits and the family tree of cancer. Nat. Genet. 32, 533-540 (2002).

29. Rouzier R, Perou CM, Symmans WF et al. Breast cancer molecular subtypes respond differently to preoperative chemotherapy. Clin. Cancer Res. 11, 5678-5685 (2005).

30. Sorlie T, Tibshirani R, Parker J et al. Repeated observation of breast tumor subtypes in independent gene expression data sets. Proc. Natl Acad. Sci. USA 100, 8418-8423 (2003).

31. Coates AS, Winer EP, Goldhirsch A et al. Tailoring therapies - improving the management of early breast cancer: St Gallen international expert consensus on the primary therapy of early breast cancer. Ann. Oncol. 26, 1533-1546 (2015).

32. Kennecke H, Yerushalmi R, Woods R et al. Metastatic behavior of breast cancer subtypes. J. Clin. Oncol. 28, 3271-3277 (2010).

33. Lowery AJ, Kell MR, Glynn RW, Kerin MJ, Sweeney KJ. Locoregional recurrence after breast cancer surgery: a systematic review by receptor phenotype. Breast Cancer Res. Treat. 13, 831-841 (2012).

34. Bauer KR, Brown M, Cress RD, Parise CA, Caggiano V. Descriptive analysis of estrogen receptor (ER)-negative, progesterone receptor (PR)-negative, and HER2-negative invasive breast cancer, the so-called triple-negative phenotype: a population-based study from the California cancer Registry. Cancer 109, 1721-1728 (2007).

35. Anders CK, Deal AM, Miller CR et al. The prognostic contribution of clinical breast cancer subtype, age, and race among patients with breast cancer brain metastases. Cancer 117, 1602-1611 (2011).

36. Ihemelandu CU, Leffall LD Jr, Dewitty RL et al. Molecular breast cancer subtypes in premenopausal and postmenopausal African-American women: age-specific prevalence and survival. J. Surg. Res. 143, 109-118 (2007).

37. Onitilo AA, Engel JM, Greenlee RT, Mukesh BN. Breast cancer subtypes based on ER/PR and Her2 expression: comparison of clinicopathologic features and survival. Clin. Med. Res. 7, 4-13 (2009).

38. McGuire A, Brown JA, Kerin MJ. Metastatic breast cancer: the potential of miRNA for diagnosis and treatment monitoring. Cancer Metastasis Rev. 34, 145-155 (2015). 
39. Buonomo OC, Caredda E, Portarena I et al. New insights into the metastatic behavior after breast cancer surgery, according to well-established clinicopathological variables and molecular subtypes. PLoS ONE 12, e0184680 (2017).

40. Scully JO, Bay HB, Yip G. Breast cancer metastasis. Cancer Genomics Proteomics 9, 311-320 (2012).

41. Jemal A, Bray F, Center MM, Ferlay J, Ward E, Forman D. Global cancer statistics. CA Cancer J. Clin. 61, 69-90 (2011).

42. Hunter KW, Crawford NP, Alsarraj J. Mechanisms of metastasis. Breast Cancer Res. 10, 2 (2008).

43. Sihto $\mathrm{H}$, Lundin J, Lundin $\mathrm{M}$ et al. Breast cancer biological subtypes and protein expression predict for the preferential distant metastasis sites: a nationwide cohort study. Breast Cancer Res. 13, 87 (2011).

44. Golubnitschaja O, Sridhar KC. Liver metastatic disease: new concepts and biomarker panels to improve individual outcomes. Clin. Exp. Metastasis. 33, 743-755 (2016).

45. Polivka J Jr, Kralickova M, Polivka J, Kaiser C, Kuhn W, Golubnitschaja O. Mystery of the brain metastatic disease in breast cancer patients: improved patient stratification, disease prediction and targeted prevention on the horizon? EPMA J. 8, 119-127 (2017).

46. Lin NU, Bellon JR, Winer EP. CNS metastases in breast cancer. J. Clin. Oncol. 22, 3608-3617 (2004).

47. Vaz-Luis I, Lin NU, Keating NL, Barry WT, Winer EP, Freedman RA. Factors associated with early mortality among patients with de novo metastatic breast cancer: a population-based study. Oncologist 22, 386-393 (2017).

48. Vardaki I, Ceder S, Rutishauser D. Periostin is identified as a putative metastatic marker in breast cancer-derived exosomes. Oncotarget 7 , 74966-74978 (2016).

49. Zeng L, Zhong J, He G et al. Identification of nucleobindin-2 as a potential biomarker for breast cancer metastasis using iTRAQ-based quantitative proteomic analysis. J. Cancer 8, 3062-3069 (2017).

50. Takahashi R, Miyazaki H, Ochiya T. The roles of microRNAs in breast cancer. Cancers (Basel) 7, 598-616 (2015).

- This review summarizes information on specific role of miRNAs during breast cancer initiation, metastasis and chemoresistance.

51. Zhang D, Jin N, Sun W et al. Phosphoglycerate mutase 1 promotes cancer cell migration independent of its metabolic activity. Oncogene 36, 2900-2909 (2017).

52. Shah MY, Ferrajoli A, Sood AK, Lopez-Berestein G, Calin GA. microRNA therapeutics in cancer - an emerging concept. EBioMedicine 12, 34-42 (2016).

53. van Schooneveld E, Wildiers H, Vergote I, Vermeulen PB, Dirix LY, van Laere SJ. Dysregulation of microRNAs in breast cancer and their potential role as prognostic and predictive biomarkers in patient management. Breast Cancer Res. 17, 21 (2015).

54. Abba ML, Patil N, Leupold JH. MicroRNAs as novel targets and tools in cancer therapy. Cancer Lett. 28, 84-94 (2017).

- This review provides comprehensive information about challenges of miRNA therapeutic techniques.

55. Mohr AM, Mott JL. Overview of microRNA biology. Semin. Liver Dis. 35, 3-11 (2015).

56. Hsu PW, Huang HD, Hsu SD et al. miRNAMap: genomic maps of microRNA genes and their target genes in mammalian genomes. Nucleic Acids Res. 34, D135-D139 (2006).

57. Fiorucci G, Chiantore MV, Mangino G, Percario ZA, Affabris E, Romeo G. Cancer regulator microRNA: potential relevance in diagnosis, prognosis and treatment of cancer. Curr. Med. Chem. 19, 461-474 (2012).

58. Westholm JO, Lai EC. Mirtrons: microRNA biogenesis via splicing. Biochimie 93, 1897-1904 (2011).

59. Hashemi M. MicroRNAs: promising potential targets for cancer treatment. Gene Cell Tissue 3, e42864 (2016).

60. Helwak A, Kudla G, Dudnakova T, Tollervey D. Mapping the human miRNA interactome by CLASH reveals frequent noncanonical binding. Cell 25, 654-665 (2013).

61. Wilczynska A, Bushell M. The complexity of miRNA-mediated repression. Cell Death Differ. 22, 22-33 (2015).

62. Liu H. MicroRNAs in breast cancer initiation and progression. Cell Mol. Life Sci. 69, 3587-3599 (2012).

63. Price C, Chen J. MicroRNAs in cancer biology and therapy: current status and perspectives. Genes Dis 1, 53-63 (2014).

64. Bartel DP. MicroRNAs: target recognition and regulatory functions. Cell 136, 215-233 (2009).

65. Kozomara A, Griffiths-Jones S. miRBase: annotating high confidence microRNAs using deep sequencing data. Nucleic Acids Res. 42 , 68-73 (2014)

66. Dweep H, Gretz N. miRWalk2.0: a comprehensive atlas of microRNA-target interactions. Nature Methods 12, 697 (2015).

67. Wong N, Wang X. miRDB: an online resource for microRNA target prediction and functional annotations. Nucleic Acids Res. 43 , $146-152$ (2015).

68. Vlachos IS, Paraskevopoulou MD, Karagkouni D et al. DIANA-TarBase v7.0: indexing more than half a million experimentally supported miRNA: mRNA interactions. Nucleic Acids Res. 43, 153-159 (2015).

69. Hsu SD, Chu CH, Tsou AP et al. miRNAMap 2.0: genomic maps of microRNAs in metazoan genomes. Nucleic Acids Res. 36, 165-169 (2008).

70. Lewis BP, Shih IH, Jones-Rhoades MW, Bartel DP, Burge CB. Prediction of mammalian microRNA targets. Cell 115, 787-798 (2003). 
71. John B, Enright AJ, Aravin A, Tuschl T, Sander C, Marks DS. Human MicroRNA targets. PLoS Biol. 2, e363 (2004).

72. Krek A, Grun D, Poy MN. Combinatorial microRNA target predictions. Nat. Genet. 37, 495-500 (2005).

73. Catalanotto C, Cogoni C, Zardo G. MicroRNA in control of gene expression: an overview of nuclear functions. Int. J. Mol. Sci. 17, 1712 (2016).

74. Matsui M, Chu Y, Zhang H et al. Promoter RNA links transciptional regulation of inflammatory pathway genes. Nucleic Acids Res. 41, 10086-10109 (2013).

75. Zhao Y, Wang F, Chen $\mathrm{S}$ et al. Methods of microRNA promoter prediction and transcription factor mediated regulatory network. Biomed. Res. Int. 2017, doi:10.1155/2017/7049406 (2017).

76. Gurses HE, Hatipoğlu OF, Gunduz M, Gunduz E. MicroRNAs as therapeutic targets in human breast cancer. In: A Concise Review of Molecular Pathology of Breast Cancer. Mehmet Gunduz (Ed.). InTech Open, London, UK, 232 (2015).

77. Wang W, Luo YP. microRNAs in breast cancer: oncogene and tumor suppressors with clinical potential. J. Zhejiang Univ. Sci. B. 16, 18-31 (2015).

78. Fuziwara CS, Kimura ET. Insights into regulation of the miR-17-92 cluster of miRNAs in cancer. Front. Med. (Lausanne) 2, 64 (2015).

79. Vilquin P, Donini CF, Villedieu M et al. MicroRNA-125b upregulation confers aromatase inhibitor resistance and is a novel marker of poor prognosis in breast cancer. Breast Cancer Res. 17, 13 (2015).

80. Shidfar A, Costa FF, Scholtens D et al. Expression of miR-18a and miR-210 in normal breast tissue as candidate biomarkers of breast cancer risk. Cancer Prevention Res. 10, 89-97 (2017).

81. Bašová $\mathrm{P}$, Pešta $\mathrm{M}$, Sochor $\mathrm{M}$ et al. Prediction potential of serum miR-155 and miR-24 for relapsing early breast cancer. Int. J. Mol. Sci. 18, 2116 (2017).

82. Kim K, Chadalapaka G, Lee SO et al. Identification of oncogenic microRNA-17-92/ZBTB4/ specificity protein axis in breast cancer. Oncogene 31, 1034-44 (2012).

83. Kurazumu S, Yamaguchi Y, Kurosumi M et al. Recent trends in microRNA research into breast cancer with particular focus on the associations between microRNAs and intrinsic subtypes. J. Hum. Genet. 62, 15-24 (2017).

84. Chaluvally-Raghavan P, Zhang F, Pradeep S et al. Copy number gain of hsa-miR-569 at 3q26.2 leads to loss of TP53 INP1 and aggressiveness of epithelial cancers. Cancer Cell 26, 863-879 (2014).

85. Gao M, Miao L, Liu M et al. miR-145 sensitizes breast cancer to doxorubicin by targeting multidrug resistance-associated protein-1. Oncotarget 7, 59714-59726 (2016).

86. Polytarchou $\mathrm{CH}$, Iliopoulos D, Struhl K. An integrated transcriptional regulatory circuit that reinforces the breast cancer stem cell state. Proc. Natl Acad. Sci. USA 109, 14470-14475 (2012).

87. Jia W, Wu Y, Zhang Q, Gao G, Zhang C, Xiang Y. Expression profile of circulating microRNAs as a promising fingerprint for cervical cancer diagnosis and monitoring. Mol. Clin. Oncol. 3, 851-858 (2015).

88. Keller A, Leidinger P, Borries A. miRNAs in lung cancer - studying complex fingerprints in patient's blood cells by microarray experiments. BMC Cancer 9, 353 (2009).

89. Iorio MV, Visone R, Di Leva G. MicroRNA signatures in human ovarian cancer. Cancer Res. 67, 8699-8707 (2007).

90. Raychaudhuri M, Bronger H, Buchner T, Kiechle M, Weichert W, Avril S. MicroRNAs miR-7 and miR-340 predict response to neoadjuvant chemotherapy in breast cancer. Breast Cancer Res. Treat. 162, 511-521 (2017).

91. Pasquinelli AE. MicroRNAs and their targets: recognition, regulation and an emerging reciprocal relationship. Nat. Rev. Genet. 13, 271-282 (2012).

92. Peter ME. Targeting of mRNAs by multiple miRNAs: the next step. Oncogene 29, 2161-2164 (2010).

93. Sohel MH. Extracellular/circulating microRNAs: release mechanisms, functions and challenges. Achievem. Life Sci. 10, 175-186 (2016).

94. Turchinovich A, Tonevitsky AG, Burwinkel B. Extracellular miRNA: a collision of two paradigms. Trends Biochem. Sci. 41, 883-892 (2016).

95. Weber JA, Baxter DH, Zhang S et al. The microRNA spectrum in 12 body fluids. Clin. Chem. 56, 1733-1741 (2010).

96. Sourvinou IS, Markou A, Lianidou ES. Quantification of circulating miRNAs in plasma: effect of preanalytical and analytical parameters on their isolation and stability. J. Mol. Diagn. 15, 827-834 (2013).

97. Boon RA, Vickers KC. Intercellular transport of microRNAs. Arterioscler. Thromb. Vasc. Biol. 33, 186-192 (2013).

98. Matamala N, Vargas MT, González-Cámpora R et al. Tumor microRNA expression profiling identifies circulating microRNAs for early breast cancer detection. Clin. Chem. 61, 1098-1106 (2015).

99. Arroyo JD, Chevillet JR, Kroh EM et al. Argonaute2 complexes carry a population of circulating microRNAs independent of vesicles in human plasma. Proc. Natl Acad. Sci. USA 108, 5003-5008 (2011).

100. Théry C. Exosomes: secreted vesicles and intercellular communications. F1000 Biol. Rep. 3, 15 (2011). 
101. Kahlert C, Kalluri R. Exosomes in tumor microenvironment influence cancer progression and metastasis. J. Mol. Med. (Berl.) 91, 431-437 (2013).

102. Roth C, Rack B, Müller V, Janni W, Pantel K, Schwarzenbach H. Circulating microRNAs as blood-based markers for patients with primary and metastatic breast cancer. Breast Cancer Res. 12, R90 (2010).

103. Pigati L, Yaddanapudi SC, Iyengar R et al. Selective release of microRNA species from normal and malignant mammary epithelial cells. PLOS ONE 5, e13515 (2010).

104. Chen X, Ba Y, Ma L et al. Characterization of microRNAs in serum: a novel class of biomarkers for diagnosis of cancer and other diseases. Cell Res. 18, 997-1006 (2008).

105. Schrauder MG, Strick R, Schulz-Wendtland R et al. Circulating micro-RNAs as potential blood-based markers for early stage breast cancer detection. PLoS ONE 7, e29770 (2012).

106. Li JY, Jia S, Zhang WH, Zhang Y, Kang Y, Li PS. Differential distribution of microRNAs in breast cancer grouped by clinicopathological subtypes. Asian Pac. J. Cancer Prev. 14, 3197-3203 (2013).

107. Riaz M, van Jaarsveld MT, Hollestelle A et al. miRNA expression profiling of 51 human breast cancer cell lines reveals subtype and driver mutation-specific miRNAs. Breast Cancer Res. 15, 33 (2013).

108. Blenkiron C, Goldstein LD, Thorne NP et al. MicroRNA expression profiling of human breast cancer identifies new markers of tumor subtype. Genome Biol. 8, R214 (2007).

109. Mattie MD, Benz CC, Bowers J et al. Optimized high-throughput microRNA expression profiling provides novel biomarker assessment of clinical prostate and breast cancer biopsies. Mol. Cancer 5(24), (2006).

110. Iorio MV, Casalini P, Tagliabue E, Ménard S, Croce CM. MicroRNA profiling as a tool to understand prognosis, therapy response and resistance in breast cancer. Eur. J. Cancer 44, 2753-2759 (2008).

111. Rask L, Balslev E, Søkilde R et al. Differential expression of miR-139, miR-486 and miR-21 in breast cancer patients sub-classified according to lymph node status. Cell Oncol. 37, 215-227 (2014).

112. Shen S, Sun Q, Liang Z et al. A prognostic model of triple-negative breast cancer based on miR-27b-3p and node status. PLoS ONE 9, e100664 (2014).

113. Schwarzenbach H. Clinical relevance of circulating, cell-free and exosomal microRNAs in plasma and serum of breast cancer patients. Oncol. Res. Treat. 40, 423-429 (2017).

114. Stückrath I, Rack B, Janni W, Jäger B, Pantel K, Schwarzenbach H. Aberrant plasma levels of circulating miR-16, miR-107, miR-130a and miR-146a are associated with lymph node metastasis and receptor status of breast cancer patients. Oncotarget 6, 13387-13401 (2015).

115. Sakurai M, Masuda M, Miki Y, Hirakawa H, Suzuki T, Sasano H. Correlation of miRNA expression profiling in surgical pathology materials, with Ki-67, HER2, ER and PR in breast cancer patients. Int. J. Biol. Markers 30, e190-e199 (2015).

116. Adams BD, Furneaux H, White BA. The micro-ribonucleic acid (miRNA) miR-206 targets the human estrogen receptor-alpha (ERalpha) and represses ER alpha messenger RNA and protein expression in breast cancer cell lines. Mol. Endocrinol. 21, 1132-1147 (2007).

117. Haakensen VD, Nygaard V, Greger L et al. Subtype-specific micro-RNA expression signatures in breast cancer progression. Int. J. Cancer 139, 1117-1128 (2016).

118. Lowery AJ, Miller N, Devaney A et al. MicroRNA signatures predict oestrogen receptor, progesterone receptor and HER2/neu receptor status in breast cancer. Breast Cancer Res. 11(3), doi:10.1186/bcr2257 (2009).

119. Zhu W, Qin W, Atasoy U, Sauter ER. Circulating microRNAs in breast cancer and healthy subjects. BMC Res. Notes 2(89), doi:10.1186/1756-0500-2-89 (2009).

120. Wang PY, Gong HT, Li BF et al. Higher expression of circulating miR-182 as a novel biomarker for breast cancer. Oncol. Lett. 6, 1681-1686 (2013).

121. McDermott AM, Miller N, Wall D et al. Identification and validation of oncologic miRNA biomarkers for luminal A-like breast cancer. PLoS ONE 9, e87032 (2014).

122. Scott GK, Goga A, Bhaumik D, Berger CE, Sullivan CS, Benz CC. Coordinate suppression of ERBB2 and ERBB3 by enforced expression of micro-RNA miR-125a or miR-125b. J. Biol. Chem. 282, 1479-1486 (2007).

123. Lu M, Wang T, He M et al. Tumor suppressor role of miR-3622b-5p in ERBB2-positive cancer. Oncotarget 8, 23008-23019 (2017).

124. Singla H, Ludhiadch A, Kaur RP, Chander H, Kumar V, Munshi A. Recent advances in HER2 positive breast cancer epigenetics: Susceptibility and therapeutic strategies. Eur. J. Med. Chem. 142, 316-327 (2017).

125. Sun G, Sun L, Liu Y, Xing H, Wang K. Her-2 expression regulated by downregulation of miR-9 and which affects chemotherapeutic effect in breast cancer. Cancer Gene. Ther. 24, 194-202 (2017).

126. Eichelser C, Flesch-Janys D, Chang-Claude J, Pantel K, Schwarzenbach H. Deregulated serum concentrations of circulating cell-free microRNAs miR-17, miR-34a, miR-155, and miR-373 in human breast cancer development and progression. Clin. Chem. 59, 1489-1496 (2013). 
127. Wu X, Somlo G, Yu Y et al. De novo sequencing of circulating miRNAs identifies novel markers predicting clinical outcome of locally advanced breast cancer. J. Transl. Med. 10(42), doi:10.1186/1479-5876-10-42 (2012).

128. Cascione L, Gasparini P, Lovat $\mathrm{F}$ et al. Integrated microRNA and mRNA signatures associated with survival in triple negative breast cancer. PLoS ONE 8, e55910 (2013).

129. Fkih M'hamed I, Privat M, Ponelle F, Penault-Llorca F, Kenani A, Bignon YJ. Identification of miR-10b, miR-26a, miR-146a and miR-153 as potential triple-negative breast cancer biomarkers. Cell Oncol. 38, 433-442 (2015).

130. Avery-Kiejda KA, Braye SG, Mathe A, Forbes JF, Scott RJ. Decreased expression of key tumour suppressor microRNAs is associated with lymph node metastases in triple negative breast cancer. BMC Cancer 14, 51 (2014).

131. Jang MH, Kim HJ, Gwak JM, Chung YR, Park SY. Prognostic value of microRNA-9 and microRNA-155 expression in triple-negative breast cancer. Hum. Pathol. 68, 69-78 (2017).

132. Mishra S, Srivastava AK, Suman S, Kumar V, Shukla Y. Circulating miRNAs revealed as surrogate molecular signatures for the early detection of breast cancer. Cancer Lett. 369, 67-75 (2015).

133. Zeng RC, Zhang W, Yan XQ et al. Down-regulation of miRNA-30a in human plasma is a novel marker for breast cancer. Med. Oncol. 30(1), 477 (2013).

134. Shin VY, Siu JM, Cheuk I, Ng EK, Kwong A. Circulating cell-free miRNAs as biomarker for triple-negative breast cancer. Br. J. Cancer 112, 1751-1759 (2015).

135. Baffa R, Fassan M, Volinia $S$ et al. MicroRNA expression profiling of human metastatic cancers identifies cancer gene targets. J. Pathol. 219, 214-221 (2009).

136. Fu SW, Lee W, Coffey $\mathrm{C}$ et al. miRNAs as potential biomarkers in early breast cancer detection following mammgraphy. Cell Biosci. 6, 6 (2016).

137. Wang SE, Lin RJ. MicroRNA and HER2-overexpressing cancer. Microrna 2, 137-147 (2013).

138. Weiland M, Gao XH, Zhou L, Mi QS. Small RNAs have a large impact: circulating microRNAs as biomarkers for human diseases. RNA Biol. 9, 850-859 (2012).

139. Cookson VJ, Bentley MA, Hogan BV et al. Circulating microRNA profiles reflect the presence of breast tumours but not the profiles of microRNAs within the tumours. Cell Oncol. (Dordr.) 35, 301-308 (2012).

140. Heneghan HM, Miller N, Lowery AJ, Sweeney KJ, Newell J, Kerin MJ. Circulating microRNAs as novel minimally invasive biomarkers for breast cancer. Ann. Surg. 251, 499-505 (2010).

141. Chan M, Liaw CS, Ji SM et al. Identification of circulating microRNA signatures for breast cancer detection. Clin. Cancer Res. 19, 4477-4487 (2013).

142. Zhu J, Zheng Z, Wang J et al. Different miRNA expression profiles between human breast cancer tumors and serum. Front. Genet. 5 , 149 (2014)

143. Bahrami A, Aledavood A, Anvari K et al. The prognostic and therapeutic application of microRNAs in breast cancer: tissue and circulating microRNAs. J. Cell Physiol. 233(2), 774-786 (2018).

144. Ye ZB, Ma G, Zhao YH et al. miR-429 inhibits migration and invasion of breast cancer cells in vitro. Int. J. Oncol. 46, 531-538 (2015).

145. Dykxhoorn DM. MicroRNAs and metastasis: little RNAs go a long way. Cancer Res. 70, 6401-6406 (2010).

146. Schrijver AME, Van Diest JP. Dutch distant breast cancer metastases consortium. Oncotarget 8, 3111-3123 (2017).

147. Gravgaard KH, Lyng MB, Laenkholm AV et al. The miRNA-200 family and miRNA-9 exhibit differential expression in primary versus corresponding metastatic tissue in breast cancer. Breast Cancer Res. Treat 134, 207-17 (2012).

148. Smeets A, Daemen A, Vanden BI et al. Prediction of lymph node involvement in breast cancer from primary tumor tissue using gene expression profiling and miRNAs. Breast Cancer Res. Treat. 3, 767-776 (2011).

149. Ono S, Lam S, Nagahara M et al. Circulating microRNA biomarkers as liquid biopsy for cancer patients: pros and cons of current assays. J. Clin. Med. 4, 1890-1907 (2015).

150. Pritchard CC, Cheng HH, Tewari M. MicroRNA profiling: approaches and considerations. Nat. Rev. Genet. 13, 358-369 (2012).

151. Thompson D, Botros I, Rounseville M. Automated high fidelity RNA expression profiling using nuclease protection coupled with next generation sequencing. HTG Mol. Diagn. 877, 289-2615 (2014).

152. Casey M, Sweeney KJ, Brown JAL, Kerin MJ. Exploring circulating micro-RNA in the neoadjuvant treatment of breast cancer. Int. J. Cancer 139, 12-22 (2016).

153. Frères $\mathrm{P}$, Josse $\mathrm{C}$, Bovy $\mathrm{N}$ et al. Neoadjuvant chemotherapy in breast cancer patients induces mir-34a and mir-122 expression. J. Cell Physiol. 230, 473-481 (2015).

154. Gezer U, Keskin S, Iğci A et al. Abundant circulating microRNAs in breast cancer patients fluctuate considerably during neoadjuvant chemotherapy. Oncol. Lett. 8, 845-848 (2014).

155. Al-Khanbashi M, Caramuta S, Alajmi AM et al. Tissue and serum miRNA profile in locally advanced breast cancer (LABC) in response to neo-adjuvant chemotherapy (NAC) treatment. PLoS ONE 11, e0152032 (2016). 
156. Zhou M, Liu Z, Zhao Y et al. MicroRNA-125b confers the resistance of breast cancer cells to paclitaxel through suppression of pro-apoptotic Bcl-2 antagonist killer 1 (Bak1) expression. J. Biol. Chem. 285, 21496-21507 (2010).

157. O’Brien K, Lowry MC, Corcoran C et al. miR-134 in extracellular vesicles reduces triple-negative breast cancer aggression and increases drug sensitivity. Oncotarget 6, 32774-32789 (2015).

158. Niu J, Xue A, Chi Y et al. Induction of miRNA-181a by genotoxic treatments promotes chemotherapeutic resistance and metastasis in breast cancer. Oncogene 35, 1302-1313 (2016).

159. Emmadi R, Canestrari E, Arbieva ZH et al. Correlative analysis of miRNA expression and oncotype Dx recurrence score in estrogen receptor positive breast carcinomas. PLoS ONE 10, e0145346 (2015).

160. Miller PC, Clarke J, Koru-Sengul T, Brinkman J, El-Ashry D. A novel MAPK-microRNA signature is predictive of hormone-therapy resistance and poor outcome in ER-positive breast cancer. Clin. Cancer Res. 21, 373-385 (2015).

161. Gong C, Tan W, Chen K et al. Prognostic value of a BCSC-associated microRNA signature in hormone receptor-positive HER2-negative breast cancer. E. Bio. Medicine 11, 199-209 (2016).

162. Du F, Yuan P, Zhao ZT et al. A miRNA-based signature predicts development of disease recurrence in HER2 positive breast cancer after adjuvant trastuzumab-based treatment. Sci. Rep. 6, 33825 (2016).

163. Anfossi S, Giordano A, Gao H et al. High serum miR-19a levels are associated with inflammatory breast cancer and are predictive of favorable clinical outcome in patients with metastatic HER2+ inflammatory breast cancer. PLoS ONE 9, e83113 (2014).

164. Kleivi Sahlberg K, Bottai G, Naume B et al. A serum microRNA signature predicts tumor relapse and survival in triple-negative breast cancer patients. Clin. Cancer Res. 21, 1207-1214 (2015).

165. Huo D, Clayton WM, Yoshimatsu TF, Chen J, Olopade OI. Identification of a circulating microRNA signature to distinguish recurrence in breast cancer patients. Oncotarget. 7, 55231-55248 (2016).

166. Kalniete D, Nakazawa-Miklaševiča M, Štrumfa I et al. High expression of miR-214 is associated with a worse disease-specific survival of the triple-negative breast cancer patients. Hered Cancer Clin. Pract. 13, 7 (2015).

167. Madhavan D, Peng C, Wallwiener M et al. Circulating miRNAs with prognostic value in metastatic breast cancer and for early detection of metastasis. Carcinogenesis 37, 461-470 (2016).

- Article is focused on the metastatic breast cancer and identify panel template of metastasis promoting, oncogenic and tumor-suppressive miRNAs, that can serve as prognostic markers for MBC, and early detection markers of metastasis in BC.

168. Clinical trials. https://clinicaltrials.gov/ct2/results?cond=Breast+Cancer\&term=miRNA\&cntry=\&state=\&city=\&dist

169. Rupaimoole R, Slack FJ. MicroRNA therapeutics: towards a new era for the management of cancer and other diseases. Nat. Rev. Drug Discov. 16, 203-222 (2017)

170. Sun Yat-Sen Memorial Hospital of Sun Yat-Sen University. microRNA of human epidermal growth factor receptor 2 (HER2) positive patient treated with herceptin. ClinicalTrials.gov Identifier: NCT02656589 (2016).

171. West Pomeranian Cancer Center. Circulating microRNA as biomarker of cardiotoxicity in breast cancer. ClinicalTrials.gov Identifier: NCT02065908 (2016).

172. Christopher AF, Kaur RP, Kaur G, Kaur A, Gupta V, Bansal P. MicroRNA therapeutics: discovering novel targets and developing specific therapy. Perspect. Clin. Res. 7, 68-74 (2016).

173. Zou Q, Yi W, Huang J, Fu F, Chen G, Zhong D. MicroRNA-375 targets PAX6 and inhibits the viability, migration and invasion of human breast cancer MCF-7 cells. Exp. Ther. Med. 14, 1198-1204 (2017).

174. Greene SB, Herschkowitz JI, Rosen JM. Small players with big roles: microRNAs as targets to inhibit breast cancer progression. Curr Drug. Targets 11, 1059-1073 (2010).

175. Rothschild SI. microRNA therapies in cancer. Mol. Cell. Ther. 2(7), (2014).

176. Kluiver J, Gibcus JH, Hettinga C et al. Rapid generation of microRNA sponges for microRNA inhibition. PLoS ONE 7, e29275 (2012).

177. Li P, Sheng C, Huang L et al. MiR-183/-96/-182 cluster is up-regulated in most breast cancers and increases cell proliferation and migration. Breast Cancer Res. 16, 473 (2014).

178. Yan LX, Wu QN, Zhang Y et al. Knockdown of miR-21 in human breast cancer cell lines inhibits proliferation, in vitro migration and in vivo tumor growth. Breast Cancer Res. 13, R2 (2011).

179. Si ML, Zhu S, Wu H, Lu Z, Wu F, Mo YY. miR-21-mediated tumor growth. Oncogene 26, 2799-2803 (2007).

180. Yang F, Li Y, Xu L et al. miR-17 as a diagnostic biomarker regulates cell proliferation in breast cancer. Onco. Targets Ther. 10, 543-550 (2017).

181. Liu S, Goldstein RH, Scepansky EM, Rosenblatt M. Inhibition of rho-associated kinase signalling prevents breast cancer metastasis to human bone. Cancer Res. 69, 8742-8751 (2009).

182. Velagapudi SP, Gallo SM, Disney MD. Sequence-based design of bioactive small molecules that target precursor microRNAs. Nat. Chem. Biol. 10, 291-297 (2014). 
183. Chen Y, Gao DY, Huang L. In vivo delivery of miRNAs for cancer therapy: challenges and strategies. Adv. Drug Deliv. Rev. 81, 128-141 (2015).

184. Stylianopoulos T, Jain RK. Combining two strategies to improve perfusion and drug delivery in solid tumors. Proc. Natl Acad. Sci. USA 110, 18632-18637 (2013).

185. Yang N. An overview of viral and nonviral delivery systems for microRNA. Int. J. Pharm. Investig. 5, 179-181 (2015).

186. Wang H, Jiang Y, Peng H, Chen Y, Zhu P, Huang Y. Recent progress in microRNA delivery for cancer therapy by non-viral synthetic vectors. Adv. Drug. Deliv. Rev. 81, 142-160 (2015).

187. Yalcin S, Gunduz U. Nanoparticle based delivery of miRNAs to overcome drug resistance in breast cancer. J. Nanomed. Nanotechnol. 7 , 414 (2016).

188. Devulapally R, Sekar NM, Sekar TV et al. Polymer nanoparticles mediated codelivery of antimiR-10b and antimiR-21 for achieving triple negative breast cancer therapy. ACS Nano. 9, 2290-2302 (2015).

189. Anand S, Majeti BK, Acevedo LM et al. MicroRNA-132-mediated loss of p120RasGAP activates the endothelium to facilitate pathological angiogenesis. Nat. Med. 16, 909-914 (2010).

190. Hayward SL, Francis DM, Kholmatov P, Kidambi S. Targeted delivery of microRNA125a-5p by engineered lipid nanoparticles for the treatment of HER2 positive metastatic breast cancer. J. Biomed. Nanotechnol. 12, 554-568 (2016).

191. Ekin A, Karatas OF, Culha M, Ozen M. Designing a gold nanoparticle-based nanocarrier for microRNA transfection into the prostate and breast cancer cells. J. Gene Med. 16, 331-335 (2014).

192. Escors D, Breckpot K. Lentiviral vectors in gene therapy: their current status and future potential. Arch. Immunol. Ther. Exp. 58, 107-119 (2010).

193. Liu Y, Lai L, Chen Q et al. MicroRNA-494 is required for the accumulation and functions of tumor-expanded myeloid-derived suppressor cells via targeting of PTEN. J. Immunol. 188, 5500-5510 (2012).

194. Iorio MV, Ferracin M, Liu CG et al. MicroRNA gene expression deregulation in human breast cancer. Cancer Res. 65, 7065-7070 (2005).

195. Lu J, Getz G, Miska EA et al. MicroRNA expression profiles classify human cancers. Nature 435, 834-838 (2005).

196. Varn FS et al. Integrative analysis of survival-associated gene sets in breast cancer. BMC Med. Genom. 8, 11 (2015).

197. Xie B, Yuan Z, Yang Y et al. MOBCdb: a comprehensive database integrating multi-omics data on breast cancer for precision medicine. Breast Cancer Res. Treat. 169(3), 625-632 (2018). 
